MILITARY TECHNICAL COLLEGE CAIRO - EGYPT

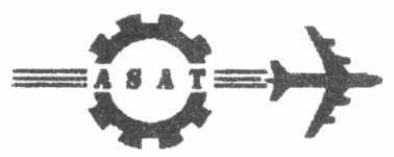

$7^{\text {th }}$ INTERNATIONAL CONF. ON AEROSPACE SCIENCES \& AVIATION TECHNOLOGY

\title{
THE CHARACTERISTICS OF CYLINDRICAL WATER-COOLED FURNACES WHEN BURNING LIQUID, GASEOUS, OR DUAL LIQUID-GAS FUELS
}

\author{
A. RAZEK A. FATTAH ${ }^{*}$, M.A. NOSIER ${ }^{* *}$, M.A. SHAHIEN ${ }^{* * *}$ and \\ N.M. ALKADI ${ }^{* * * *}$
}

\begin{abstract}
Measurements inside a tlame tube are presented and compared for a range of confined liquid fuel oil, gasẹous fuel and dual fuel flames. The operating conditions include a range of three heat inputs $29 \mathrm{~kW}, 38 \mathrm{~kW}$ and $48 \mathrm{~kW}$. For dual fuel tlames three gaseous fuel ratios $25 \% ; 50 \%$ and $75 \%$ are considered. The experimental work takes place using an industrial type, dual fuel burner that is especially designed and constructed to utilize the three types of firing. This burner is fitted to a water cooled cylindrical furnace (the Combustor).
\end{abstract}

It is found that, Burning gaseous fuel simultaneously with liquid fuel oil, acts as a hot shield surrounding the oil spray tlame. This shield serves to reduce significantly the loss of combustibles from oil flames, mainly through enhancing the evaporation process of fuel oil droplets and increasing soot burnout at the flame region as well as preventing the surviving soot particles from being deposited on furnace walls. The importance of these conclusions emerges when burning low grade fuels or bituminous fuels which needs a more carefully designed combustion system.

\section{KEY WORDS}

Combustion, Liquid Fuel, Gaseous Fuel, Dual Fuel, Burners, Combustor Efficiency, Soot Emission.

* Professor of Mechanical Engineering. Helwan University. Cairo, Egypt. ** Associate Professor of Mechanical Engineering. Ain Shams University. Cairo. Egypt. ***A Associate Professor of Mechanical Engineering, Helwañ University. Cairo, Egypt. **** Mechanical Engineer. Organization for Energy Conservation and Planning, Cairo. Egyrt. , 


\section{NOMENCLATURE}

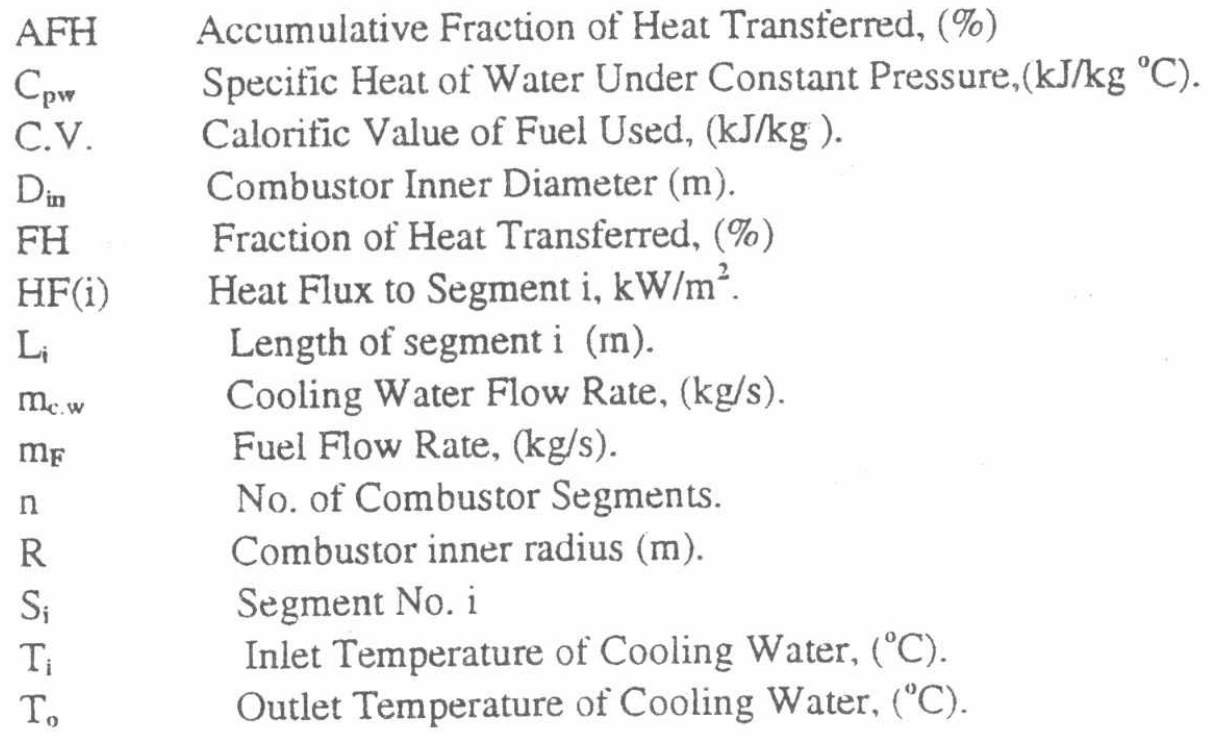

\section{INTRODUCTION}

The main concern in furnaces, boilers and gas turbines design is to obtain a stable flame, with high combustion efficiency and minimal noise and emission levels at a wide range of operating conditions. Such flame would allow for more energy savings and for lower environmental pollution.

The core of any combustion system is its burner. Continuous research and development work are carried out by the burners manufacturers in order to achieve the above aims. A large amount of information and research work are available for single fuel burners and multifuel burners which are designed to burn more than one type of fuel, but not simultaneously [1-20]. This is why sufficient information for simultaneous burning of more than one type of fuel, is scarce. With the increasing availability of Natural Gas in Egypt, emphasis has been placed on obtaining sufficient information for the effect of using gaseous tuel instead or along with the presently used liquid oils. Those information would contribute to a hasic understanding of the structure and characteristics of dual fuel flames.

\section{EQUIPMENT AND EXPERIMENTAL WORK}

\subsection{Test Rig Description}

The experimental arrangement is shown in Fig. 1. It comprises the combustor which is a horizontal cylindrical water-conled tlame tube of $(1.4 \mathrm{~m}$ inside diameter and $2.0 \mathrm{~m}$ long. Cooling is via water jacket which is divided into thirteen axial segments. Each segment 
receives water at room temperature, and discharges it to drain. The Combustor is fitted with a coaxial dual fuel burner as illustrated in Fig. 1. The construction of the burner used is similar to those commonly used in large power stations and petroleum refineries in Egypt and probably elsewhere; (e.g. Abou-Sultan power station). It is a double-swirl type: the two swirlers are concentric as shown in Fig. 2. In this arrangement, a liquid fuel oil is sprayed by a $60^{\circ}$ swirl atomizer placed at the center of the primary (inner) air swirler of $45^{\prime \prime}$ vane angle. Four identical holes were opened through the vanes of the outer secondary air swirler of 3()$^{\circ}$ vane angle to allow for the fixation of four identical gaseous fuel burners. These gaseous burners are placed off-axis of combustor, and distributed at equal circumferential distance along a circle having a diameter of $0.136 \mathrm{~m}$. Hence they are mounted at the ends of two perpendicular diameters of that circle as shown in Fig. 2 Combustion air is supplied to the burner by an electric air blower. The air flow rate is measured by a standard, calibrated orifice plate connected to a U-tube water manometer The liquid fuel used is gas oil (solar) with an approximate weight analysis of $86.3 \% \mathrm{C}$ $12.8 \% \mathrm{H}_{2}, 0.90 \% \mathrm{~S}$. The average heating value and density are $44162 \mathrm{~kJ} / \mathrm{kg}, 820 \mathrm{~kg} / \mathrm{m}$ respectively. The liquid fuel mass tlow rate is measured by means of pressure gauge indicator which is calibrated to read the mass tlow rate. The gaseous fuel used is a commercial LPG fuel with a volumetric approximate analysis of $70 \%\left(\mathrm{C}_{4} \mathrm{H}_{10}\right)$ and $30 \%$ $\left(\mathrm{C}_{3} \mathrm{H}_{8}\right)$ and an average heating value of $47092 \mathrm{~kJ} / \mathrm{kg}$. The gaseous fuel mass flow rate through each gas burner is measured by means of a calibrated orifice meter.

In the present work, average flame temperature is measured using a fine-wire thermocouple, water-cooled probe. The hasic design has been previously used by many investigators $[7,10]$. The thermocouple is made of Platinum and $10 \%$ Rhodium-Platinum wires of $100 \mu \mathrm{m}$ diameter and connected to an electronic integrator and a millivolt- mete The soot concentration is measured using the well known Bacharach tester. The heat flux to the combustor walls is measured through the measurements of the specific enthalpy rise and the flow rate of cooling water in each segment. The enthalpy rise is calculated hy measuring the cooling water temperature difference between outlet and inlet. The coolin water tlow rate in each segment is determined by collecting a certain volume of the outlet water and measuring the corresponding time $[18]$. Provisions were made to check the flow rate through each segment at least two times lor each run. The outlet water temperature it cach segment was measured hy type E thermocouple (Nickel Chromium - Copper Nicke) which is located at the segment exit. The values of temperature are displayed on digitial thermometer having a resolution of (1). " $^{\circ} \mathrm{C}$. The heat thux to each segment is calculate 1 using the simple lormula :

$$
H F_{n}=\frac{\left[m_{w} \times C_{n w} \times\left(T_{n}-T_{i}\right)\right]_{\cdots}}{\left(\Pi \times D_{n} \times L_{i}\right)}
$$




\subsection{Experimental Procedure.}

The aim of the experimental procedure is to investigate and to compare both the flame structure and the characteristics of the combustor under three types of firing. These types of firing are :

1. Liquid fuel firing.

2. Gaseous fuel firing.

3. Dual (simultaneous) fuel firing.

A range of three heat inputs are included in each firing type. These chosen three heat inputs are $29 \mathrm{~kW}, 38 \mathrm{~kW}$ and $48 \mathrm{~kW}$ with an excess air factor of $20 \%$ which is kept constant during the groups of test runs. Also, for the dual fuel firing where liquid fuel and gaseous fuel are fired simultaneously, three gaseous fuel ratios are chosen namely; $25 \%$, $50 \%$ and $75 \%$. Accordingly, a total of 15 test runs are carried out. The operating conditions for these runs are shown in table 1, whereas Fig. 3 exhibits photographs for the corresponding flames.

\section{DISCUSSION OF RESULTS}

\subsection{Liquid Fuel Oil Flame Structure.}

The experimental results obtained for the three oil flames of runs 1,2 and 3 together with visual observations, allowed the formulation of a physical description of the tlame structure common to the three flames. The liquid fuel oil leaves the atomizer in the form of a hollow conical spray with a central air core. The swirled combustion air creates a recirculation zone which surrounds the fuel atomizer, as also observed previously, e.g. Chigier[25]. The spray sheet travels through this reverse flow zone and as a result, small droplets and fuel vapour are recirculated inside this zone. In addition, the presence of this recirculation zone displaces droplets found near the centerline towards the outer edge of the spray. This results in a transportation of a number of droplets outside the nominal spray houndary, Presser et al.[1]. Across the shear layer, which encloses the recirculation zone. the high turbulent mixing rates and the comparatively high temperature of the recirculated gas allowed chemical reaction to proceed with a high intensity. This region extends to the fuel spray region and there, the resulting high temperature increases the droplets evaporation and helps to stabilize the flame. The radial protiles of temperature tor the three oil tlames of runs 1.2 and 3 are shown in Fig. A. Although the temperature profiles for the three oil tlames indicale the same general trend. quantitative differences exist in the temperature values and in the relative dimensions of the central high intensity combustion, high temperature zone. The comperature increases appreciably across the thame houndaries e.g. at axial location of $x / D=() .125$ and $r / R=() .2$. Far downstream lucations. at $x / D>0$. 625 , the combustor is lully occupied with non-luminous combustion gases and the temperature levels exhihit gradual decline along the combustor down-stream dircetion due to convective heat transfer to the cooling jacket. The shape of these profiles (ends to even-out due to turbulent diffusion elfects. The final concentration of soot at exit 
is expected to be determined by the combined effects of formation and burnout, which are intluenced by the temperature throughout the tlame [14]. In general, high temperature levels lead to lower soot concentration. It is clear, therefore, that the values of temperature and soot concentration are different when comparing the three oil flames of runs 1,2 and 3 . These differences may be attributed to the spray quality of each flame which indirectly affects the temperature field. The droplet size which is greatly affected by the fuel atomization pressure plays a major role in the combustion performance of spray tlames, Chigier[25]. The three flames correspond to three atomizing pressures namely; $3.5,7.5,12$ bars. For the flame of run 1, the slow evaporation of its comparatively large droplets provides a small amount of fuel vapor at the spray region and, therefore, the dilution and quenching of chemical reaction effects of the surrounding air stream will result in a reduction in the combustion intensity. This is supported by the relatively low temperature values measured along the combustor. In addition, it is also confirmed by the relatively high accumulation rates of condensed fuel vapor experienced in the sampling system during soot concentration measurements. For the flames of runs 2 and 3 which are characterized by higher atomization pressures, larger number of finer droplets and hence faster evaporation rate is experienced. Accordingly, an intense chemical reaction will he ensured, leading to elevated temperature levels. This is evident by referring to Figs. $4\left(b^{\circ}, c\right)$ which show a higher temperature values compared to the oil flame of run 1 shown in Fig. (4.a).

\subsection{Gaseous Fuel Flame Structure.}

The flames of the gas burners used are partially premixed, by , virtue of the existing ports of the burner tube. The tuel/air mixture issuing from the burner entrains secondary air from the combustor space, intermingle with it, and burns intensely with a blue-coloured tlames, see Fig. 3. Such premixing results in a single peak of temperature that coincides nearly on gas hurner centerline, which is strictly true at close distances from gas burner exit. This is clear in Fig. 5 (a.h.c) where the maximum temperature occurs at $r / R=() .30$ and $x / D=() .125$. At further downstream locations, tempeiature values tend to fall off, and even out across the combustor tlow cross-section, mainly due to heat transter to walls and gas mixing, augmented by swiri motion. The level of snot for the gaseous flames is found negligible, which indicates the clean combustion pattern of gaseous flames.

\subsection{Dual Fuel Flame Structure.}

a. Gaseous Fuel Ratio $25 \%$.

For such low gas fuel ratio (runs 7.8.9) the gaseous four flames are ux small (o) signilicantly interact with the oil llame. refer (o) Fig. 3. However. the existence of gavenous flanes around the oil thame seems lo improve, somehow. the evaporation of some licel on droplets in the near region of gas hurners. This is consistent with the reduction in soot levels at combustor exit in this case, as shown in Fig. 6. compared with the corresponding levels of pure fuel oil thames. Close inspection to these ligures suggests that the hasic dual 
tuel flame structure has a combined features of both oil tlames and gaseous flames. As shown in Fig. 6, two peak temperature values are recorded at $x / D=0.125, r / R=0.15$ and (0.35. The first peak corresponds to the oil flame whereas the second to the gaseous thame. The spreading of the oil tlame seems to be slightly reduced at $x / D=0.375$ compared to the cases of pure oil tlames, compared with Fig. 4. This is attributed to the existence of the four gaseous flames that contributes, in this case, to some extent in rectifying the oil flame.

\section{b. Gaseous Fuel Ratio 50\%.}

The radial temperature at different axial locations are shown in Fig. 7 for the flames having gaseous fuel ratio of $50 \%$ which correspond to runs $10,11,12$. During these runs, gaseous fuel tlow rates are increased whereas liquid fuel oil rates are decreased while maintaining the same fixed three heat inputs mentioned above. Although the reduction in fuel oil rates was accompanied by a corresponding reduction in fuel oil atomizing pressure, the existence of the four gaseous tlames seem to compensate the drawback of this by modifying the evaporation characteristics of the fuel oil droplets. It is also observed that the soot concentrations at the exhaust port of the combustor during these runs are lower than those of the cases of $25 \%$ gas-fuel ratio (runs 7,8 and 9 ).

\section{c. Gaseous Fuel Ratio $75 \%$.}

Under this high value of gaseous fuel rates, (runs 13-15), great interaction seems to occur between the oil flame and the gasenus flames. The colour of the oil flame is converted from a dark luminous tlame to a bright luminous one characterised by lower levels of soot formation and higher levels of temperature compared to runs (1-3 and 7-12) which relate to cases of lower gaseous ratio. In addition, the existence of this intense interaction hetween the flames greatly contributes in shortening the oil flame length via accelerating evaporation of oil droplets. Fig. 8 illustrates the radial protiles of temperature. In comparison with the case of less gaseous fuel ratio, it is observed that the region of interaction hetween gaseous tlames and fuel oil tlames is further extended to cover more space in the fuel oil tlame. The gaseous fuel tlame seems to survive up to $x / D=() .375$. manifested hy the single peak temperature whereas the oil thame peak temperature is ulmost vanished.

\subsection{Heat Flux Distribution to The Combustor Walls.}

Fig. 9(a.h.c) shows the heat hux distritution we the combuster walls at different heat inputs and under different types of liring. As a common teature. heal tlux peaks at about $x / D=(1) .25()$. where this region is characterized hy an intense chemical reaction as well as favourite radiation characteristics. The effect of varying the heat input on the peak heat llux was found (o) die down as the gaseous lued ratio increased. For example lor pure oilfuet thame, it was found that increasing the heat input from 29 (1) $48 \mathrm{~kW}$ would increase the peak heat llux hy ád factor of 2.28. ()n the other hand this same factor is redueed of 1.71 for the 17 ame of $75 \%$ gaseous luet ratio, and reduced even further 6 only 1.57 for 
the pure gaseous-fuel tlame. This indicates that using gaseous fuel simultaneously with it liquid-fuel tlame would cause the heat flux peak value to be less sensitive to variations in heat input to the combustor (i.e. versus variable load operation of the combustor). This may he attributed to the sensitivity of the atomization process of oil flames under variable load. A process whose effect is overshadowed when gaseous tlames coexist with oil tlames.

\subsection{The Accumulative Heat Transferred to The Walls.}

The accumulative heat transferred to the combustor walls equals the sum of the heat transferred to all segments of the wall. For any segment, for example no.(i), the fraction of heat transferred to it is given by :

$$
F H_{(i)}=\frac{\left[m * \times C p_{v} \times\left(T_{0}-T_{n}\right)\right](i)}{(m \times C . V .)} \times 100 \%
$$

The accumulative fraction of heat transferred that is given off by the flame up to segmen: no.(n) is given by :

$$
(A F H)(n)=\sum_{i=1}^{i=n} F H(i)
$$

If ' $\mathrm{n}$ ' in this equation designates the last segment of the wall, (AFH) value would equal the total traction of heat transferred to the combustor wall , i.e. equals the thermal efficiency of the combustor $[17,22]$.

As shown in Figs. 1()$(a, b, c)$ for a fixed heat input, increasing the gaseous fuel ratio greatly increases the accumulated heat transferred. This result directly reflects a favourite effect of introducing gaseous flames together with oil tlames. This is mainly due to the contribution (1). gaseous tlames in enhancing the evaporation and combustion characteristics of oil flames specially at poor atomizing conditions which is likely to ensue, for example, at low oil fuel percentage..

\subsection{Thermal Efficiency of The Combustor and Soot Concentration at Exhaust Port}

Figs. 11 and 12 show comprehensive comparisons of the combustor characteristics unde! different types of fued admitted and at different heat inputs. Fig. 11 shows the effect of gaseous ratio and heat imput on thermal efficiency while Fig. 12 presents the effect of the same two variahles on soot levels at combustor exit. These ligures indicate that therma efficiency of the combustor can he raised and soot cmission levels reduced hy means or the following two actions:

a) increasing the gaseous fuct ratio : or

h) increasing the heat input. 


\section{CONCLUSIONS}

From observations and analysis of the experimental results, the following main conclusions may he summarized as follows :

1. Adoption of the gas flame jets, placed around the central oil flame, assisted by the swirling motion of air, acts as a hot jacket to the oil tlame. This jacket reduces significiantly the loss of combustibles from the oil flame, presumably through evaporating and hurning the falling and flying oil droplets and soot particles

2. For a fixed heat input, increasing the gaseous fuel ratio, has the following advantages:

(a) Faster attainment of uniform radial distribution of temperature which augments the convective heat transfer rates.

(b) Obtaining more uniform heat flux along the combustor downstream direction.

(c) Increasing the accumulative heat transfer to the combustor walls, and consequently raising the thermal efficiency.

(d) Reducing the soot concentration levels at combustor exit.

(e) Less sensitivity of the peak value of the heat flux to variations of heat input (i.e. versus variable load of the combustor)

3. For the three types of firing examined, under the volume and configuration of the present combustor, an increase in loading(heat input) within the tested range (29-48 $k W)$, causes an increase in both heat flux intensity and thermal efficiency.

4. The adoption of dual fuel firing makes it easy to control heat transfer mode and streamwise distribution of heat flux. Thus dual firing with low gas ratio should be adopted for a principal radiative-heat-transfer-mode with a peak at the region close to the burner end. On the other hand dual tiring with high gaseous fuel ratio may be used for a process that is dependent on convective heat transfer mode with a rather more uniform heat tlux distribution.

\section{REFERENCES}

1. Presser,C., Gupta,A.K. and Semerjian,H.g., "Droplet Transport in a Swirl-Stabilized Spray Flames," The eighth International Conference for Mechanical Power Engineering, Alexandria University, Alexandria, Egypt, April, 1993.

2. El-Mahallawy.F.M., Farag,S.A. and Yowakim, F.M.," Effect of Some Parameters on the Radiant Heat transter in a Cylindrical Oil-Fired Furnace," First Conference of Mechanical Power Engineering, Cairo University, Cairo, Egypt, Feb. 1977. 
3. El-Mahallawy,F.M., Khalil,E.E and Abdel Aal O., "Characteristics of Water Cooled Flame Tube," Fourth International Conference for Mechanical Power Engineering, Oct., Cairo, Egypt, 1982.

4. Moneib, H.A., Ismail, M.A., and Hussien, A.M.," Characteristics of Swirling Oil Flames in a Cylindrical Furnace with Variable Quarl Geometry," 7th International Conference of Mechanical Power Engineering, Cairo University, Vol. II , Dec. 1990.

5. El-Mahallawy,F.M., Hassan,M.A. and Eid, M. H., "Influence of Firing Parameters on Oil Fuel Combustion in Flame Tubes." The Eighth International Conference for Mechanical Power Engineering, Alexandria University, Alexandria, Egypt, April, 27-29. 1993.

6. El-Banhawy,Y.H.,Elehwany,A.A. and Hagag,E.a.,"The Combustion Characteristics of Swirl/Disc-Stabilized Spray Flames," Seventh International Conference of Mechanical Power Engineering, Cairo University, 1990.

7. El-Mahallawy,F.M., Mahdi Ali,E. and Rashad, "Characteristics of Combustion Heat Liberated Down Stream of Circular Bluff Bodies," Proceeding of Second Conference of Mechanical Power Engineering, Vol.2, 1978, Cairo, PP. 1-12.

8. El-Banhawy,Y.H., and Whitelaw,J.H.," Experimental Study of The Interaction Between a Fuel Spray and Surrounding Combustion Air," Combustion and Flame, Vol.42, 1981, PP.253-275.

9. El-Banhawy,Y.H., " Open and Confined Spray Flames," Ph.D.Thesis, University of London. England, 1980.

10. Elghoroury,S. Abdullah," Effect of Stabilizing Cone Angle and Swirling Action on Confined Flame structure," Ph.D, Thesis, Cairo University, 199().

11. Wu. H.L. and Fricker, N.,"The characteristics of Swirl Stabilized Natural Gas Flames," Journal of the Institute of Fuel, 1976 PP. 144-151.

12. Yuasa. S.. "Elfect of Swirl on the Stability of Jet Diffusion Flames," Combustion and Flame Journal, Vol.66, PP. 181- 192. 1986,.

13. El-Mahallawy, F.M., and Abbas, A.S.." Etfect of Swirling of Fuel and Air Streams "ff Heat Liheration in Cylindrical Gas Furnace," Bulletin of the Faculty of Engineering, Cuiro University, 1978. 
14. Nishida,Osami and Mukohara,seiya," Characteristics of Soot Formation and Decomposition in Turbulent diffusion Flames," Combustion and Flame, Vol. 47, 1982, PP 269-279.

15. Adel Salam,M.S.," Heat Transfer in Cylindrical Flame Tubes," Proceeding of second conference of Mechanical Power Engineering, Cairo, September, 1978.

16. El-Mahallawy, F.M., Ali,E.Mahdy, Negm,S.M. and Rafat,N.M.," An Experimental Investigation of The Effect of Exit Section Geometry and Furnace Length on Heat Liberation in a Cylindrical Gas Fired Model Furnace," Proceeding of second Conference of Mechanical Power Engineering, Cairo, September, 1978.

17. H.L., WU. "Comparison of the Performance of Natural Gas and Oil Flames in a Cylindrical Furnace," Journal of the Institute of Fuel, pp 316-323, August, 1969.

18. Barakat, H.Z. and Gad EL-Mawla. "Study of the Performance of Radiant Type Furnace When Firing Gaseous and Liquid-Gas Fuel,." Second Conference of Mechanical Power Engineering, Cairo, September, 1978.

19. Sabry, T.I., Elaskary, A.H., Sheta, M.M. and Mohamed,E.A., "Theoretical Analysis on Heat Transfer From Diffusion Flames with Gaseous Fuel Injection," The Eighth International Conference for Mechanical Power Engineering, Alexandria University, Alexandria, Egypt, April 27-29, 1993.

2). Ibrahim Said, M.A., Moneib, H.A. and Waley, M., " Structure and Radiative Properties of Pulverized Coal/Gas/Air Jet Flames," Seventh International Conference of Mechanical. Power Engineering. Cairo University, 199().

21. Chigier, N., "Optical Imaging of Sprays," Progress of Energy and Combustion Science, Vol. 17, PP 21:1-262, 1991. 


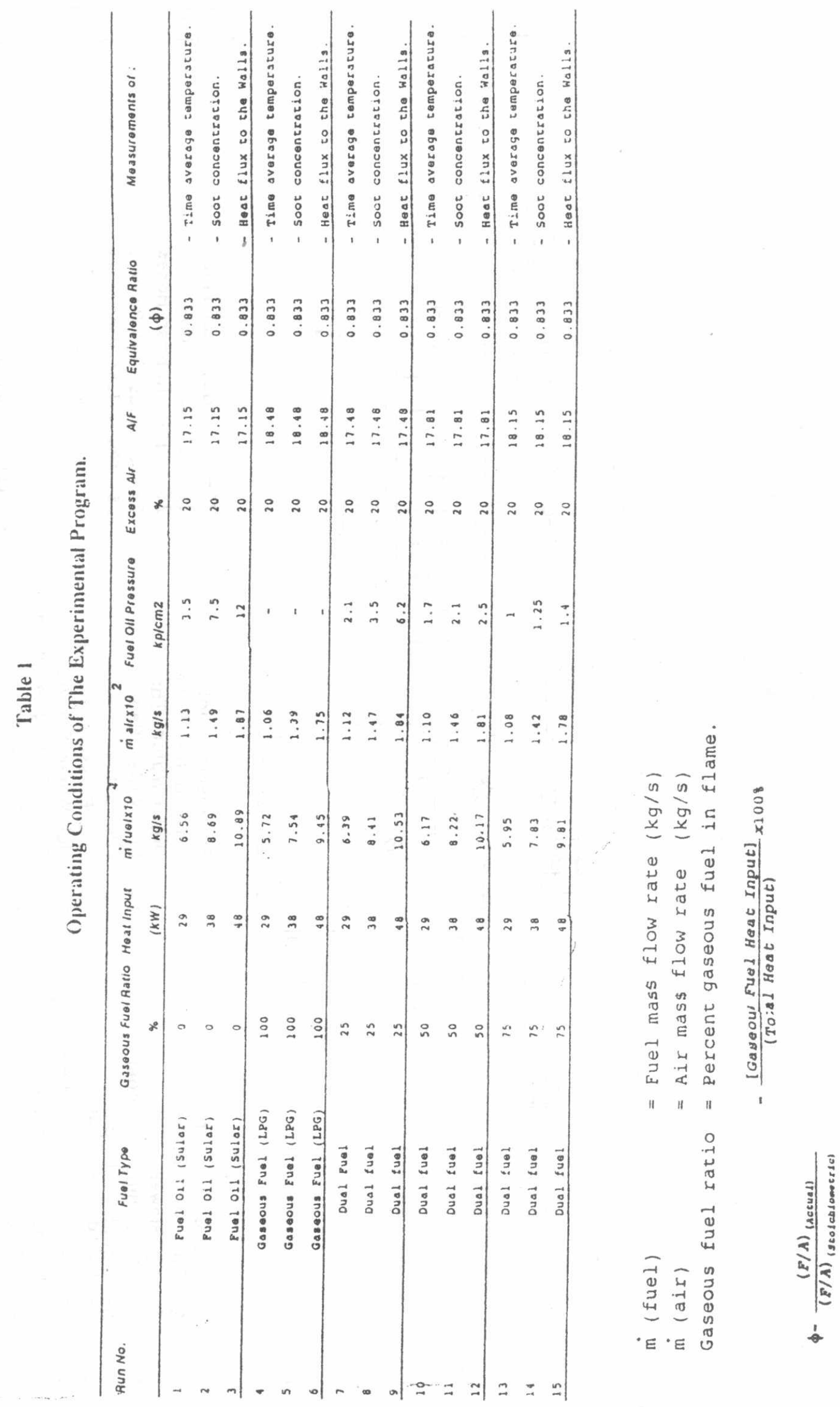




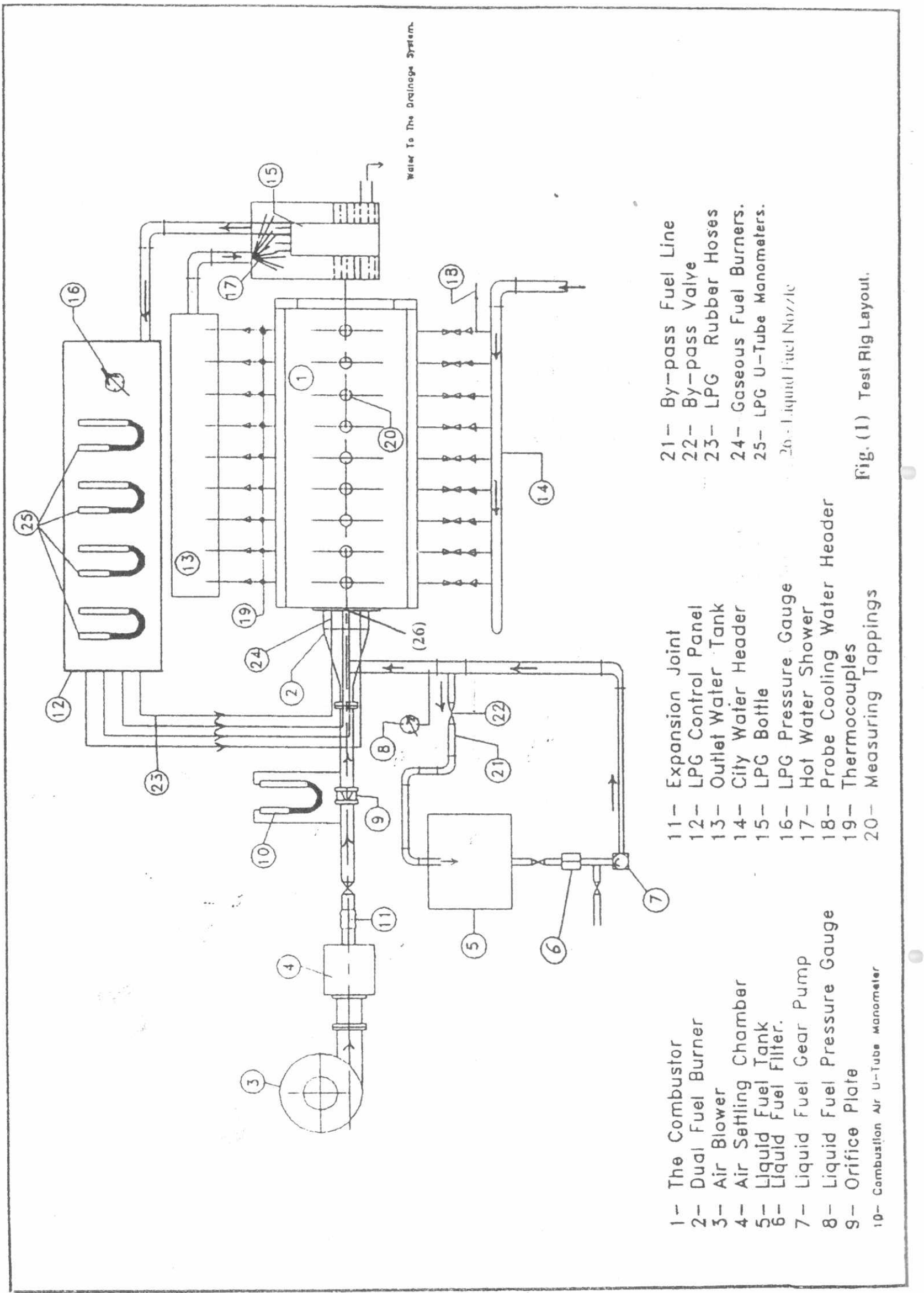




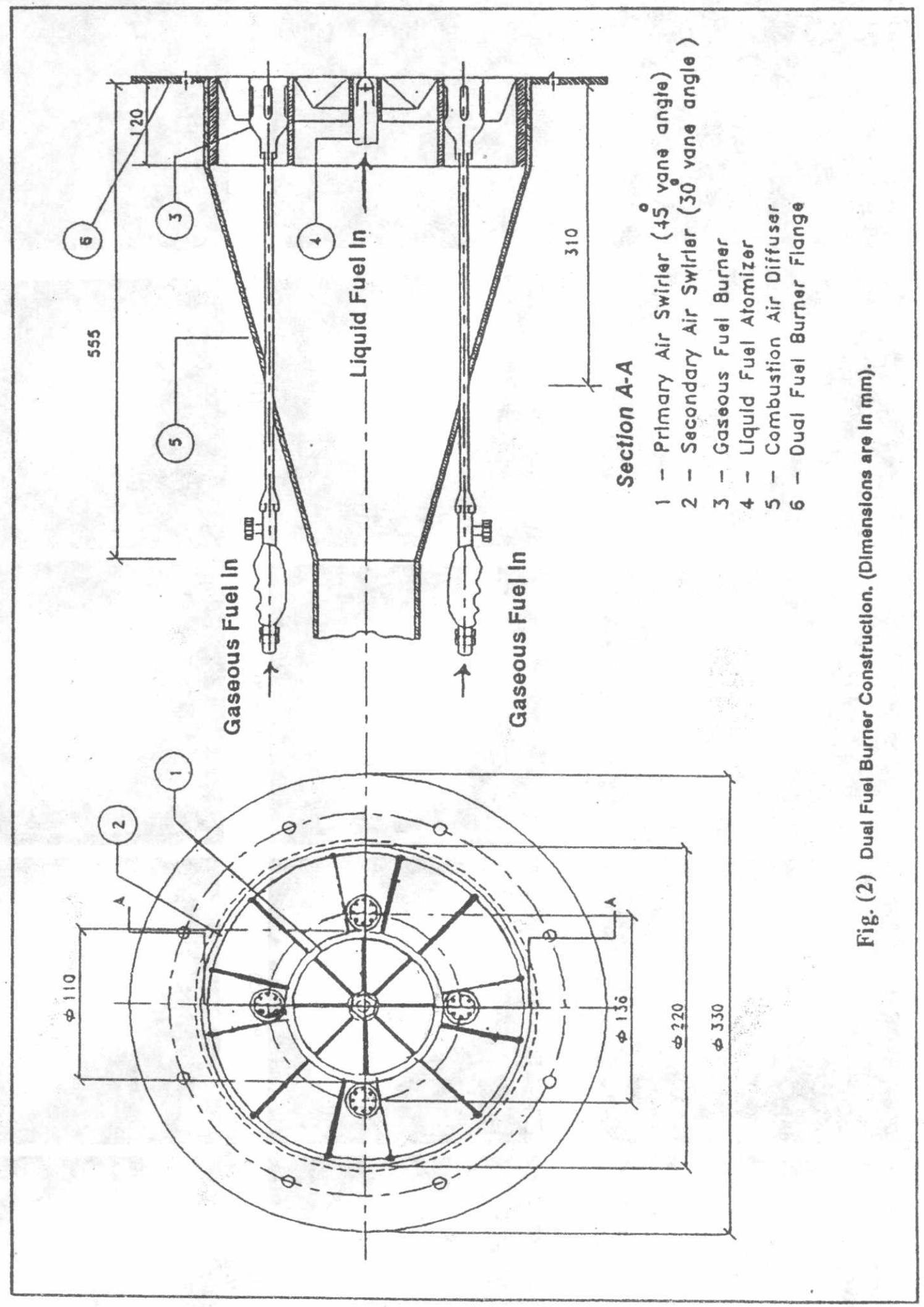



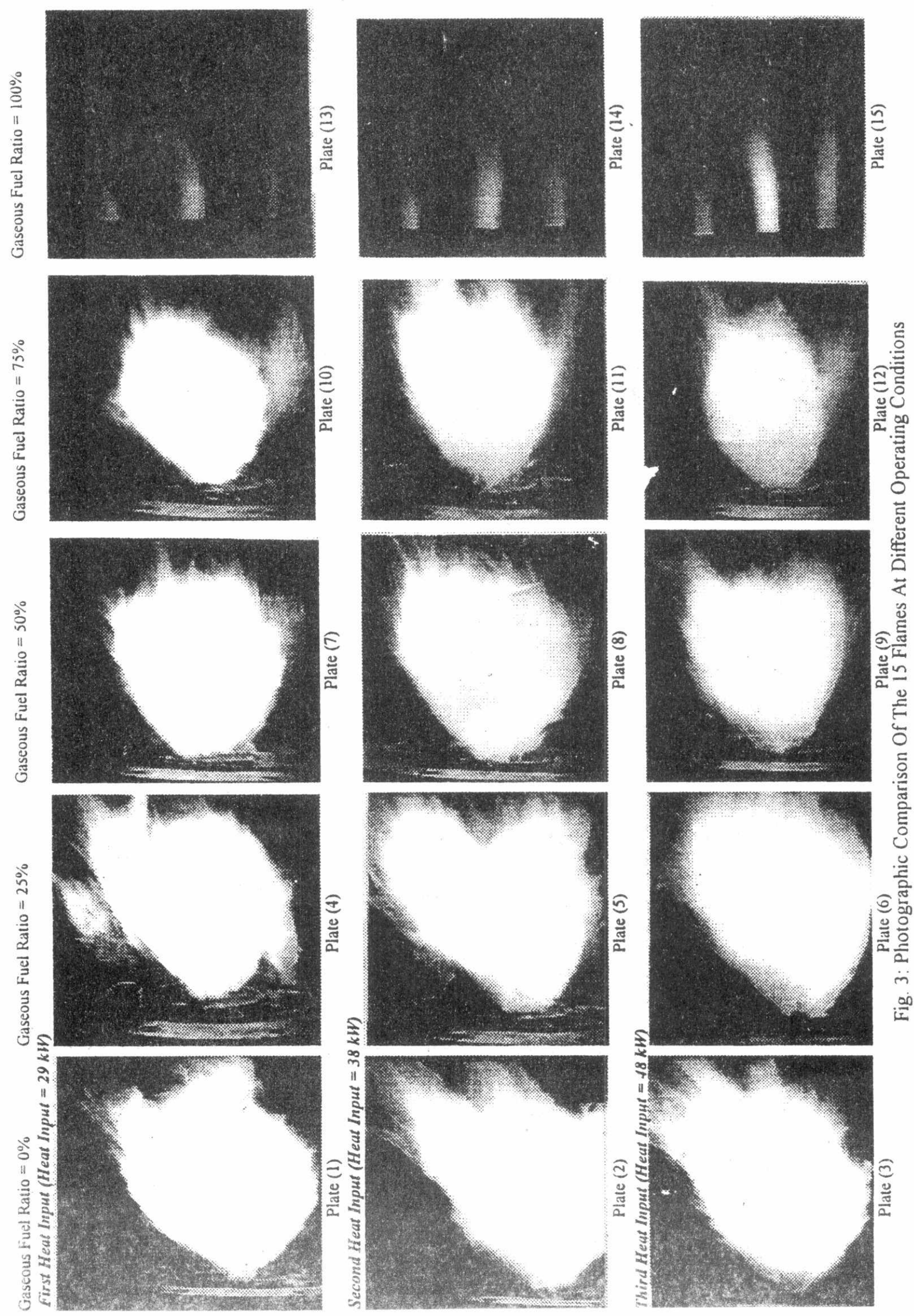


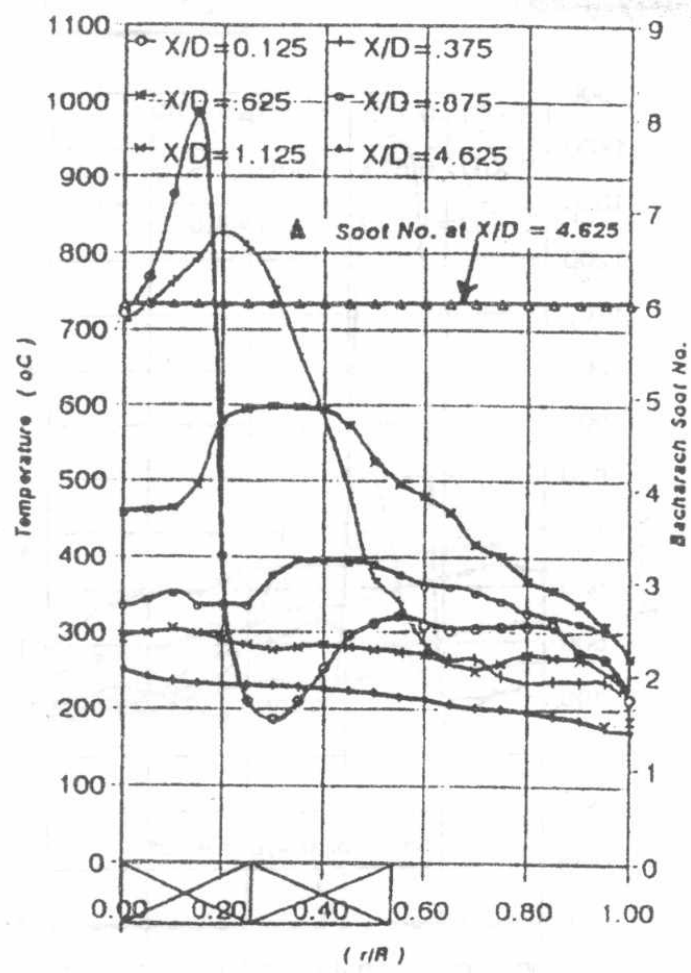

(a) - Run 1

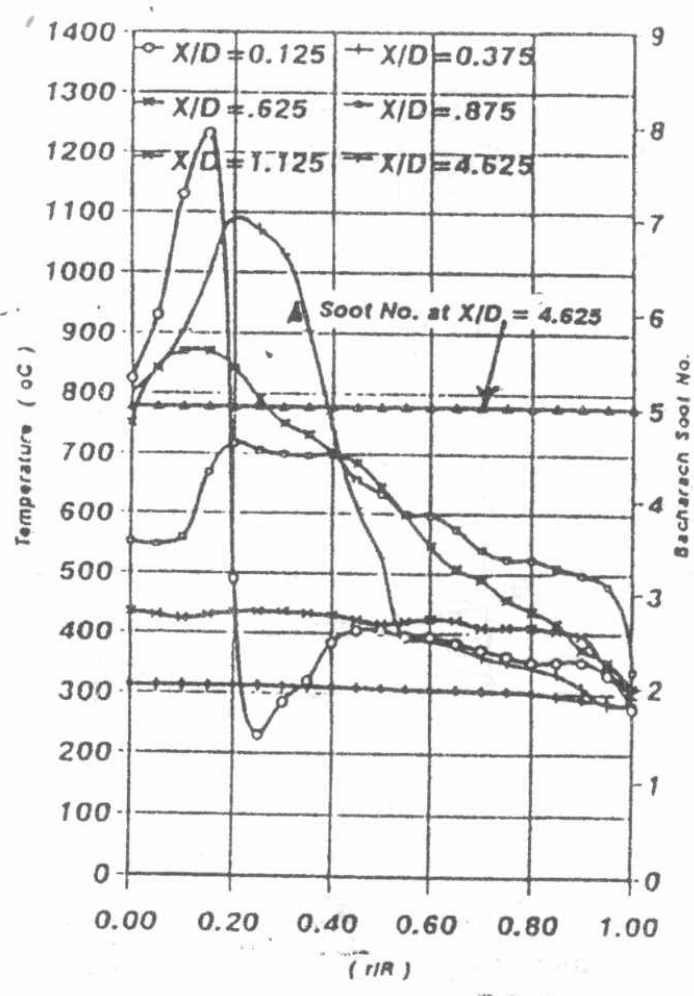

(b) - Run 2

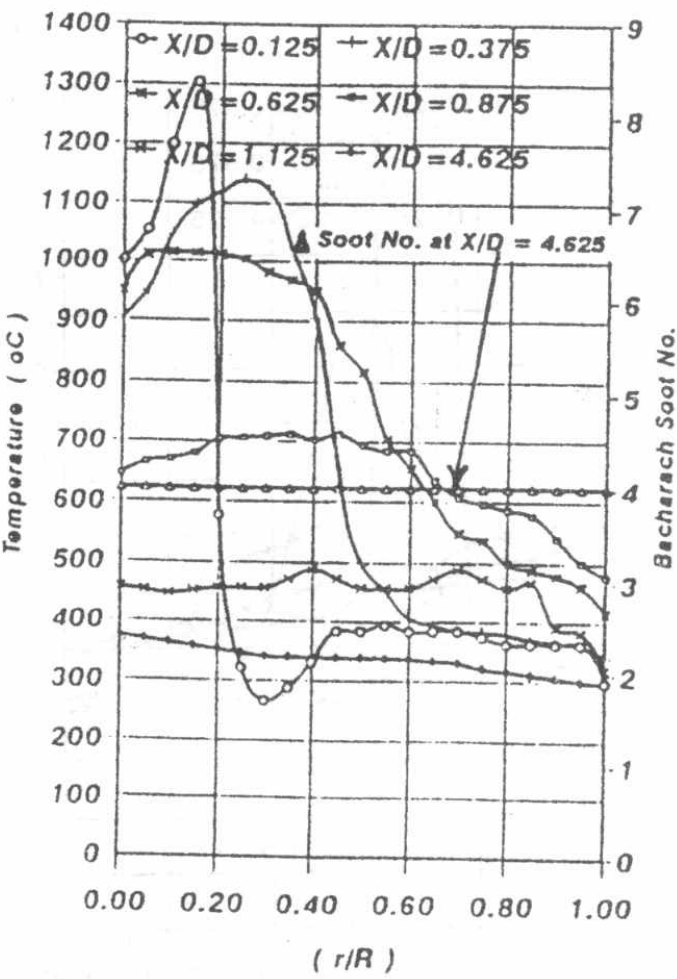

(c) - Run 3

Fig. 4 Radial Proflies of Temperature at Different Axial Locations and Sool Concentration at Combustor Exit - Runs 1,2,3.

Fuel Type : Fuel Oll (Solar)- Gaseous Fuel Ratlo $=0 \%$.

(a) Heat input $=29 \mathrm{~kW}$

(b) Heat Input $=38 \mathrm{~kW}$

(c) Heat input $=48 \mathrm{~kW}$

Equ1valonce Ratlo( $(\phi)-0.833$ 


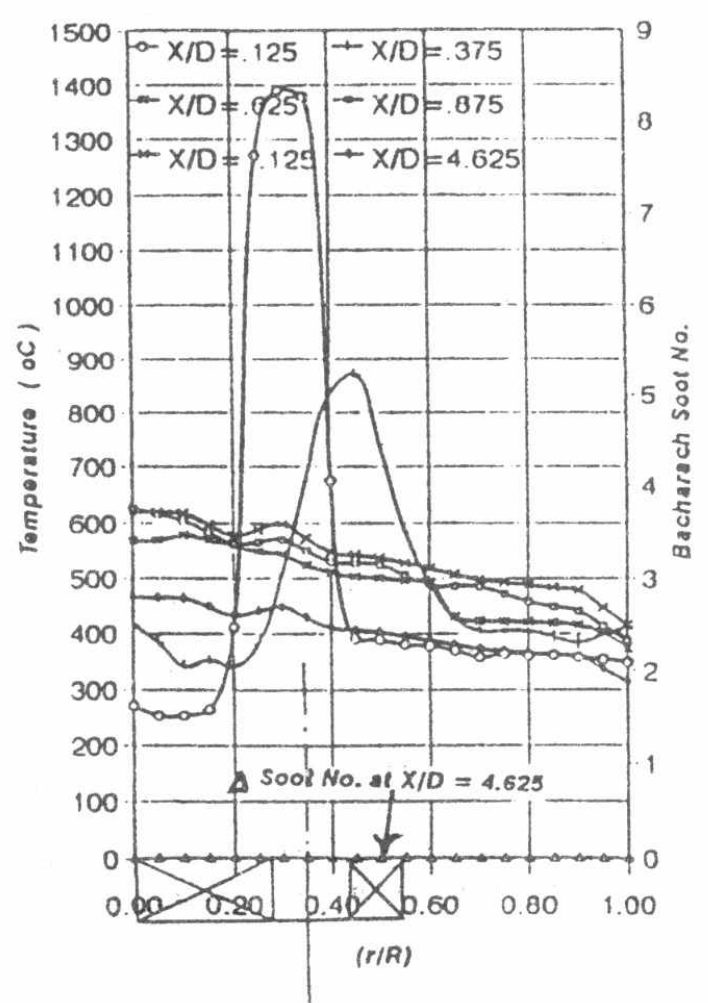

(a) - Run 4

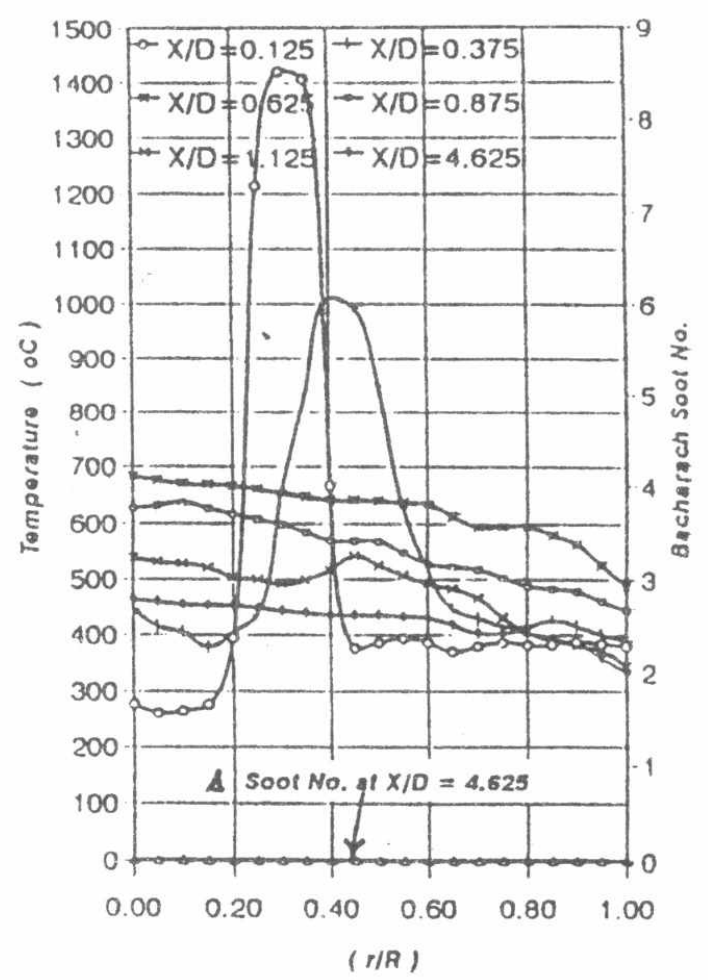

(b) - Run 5

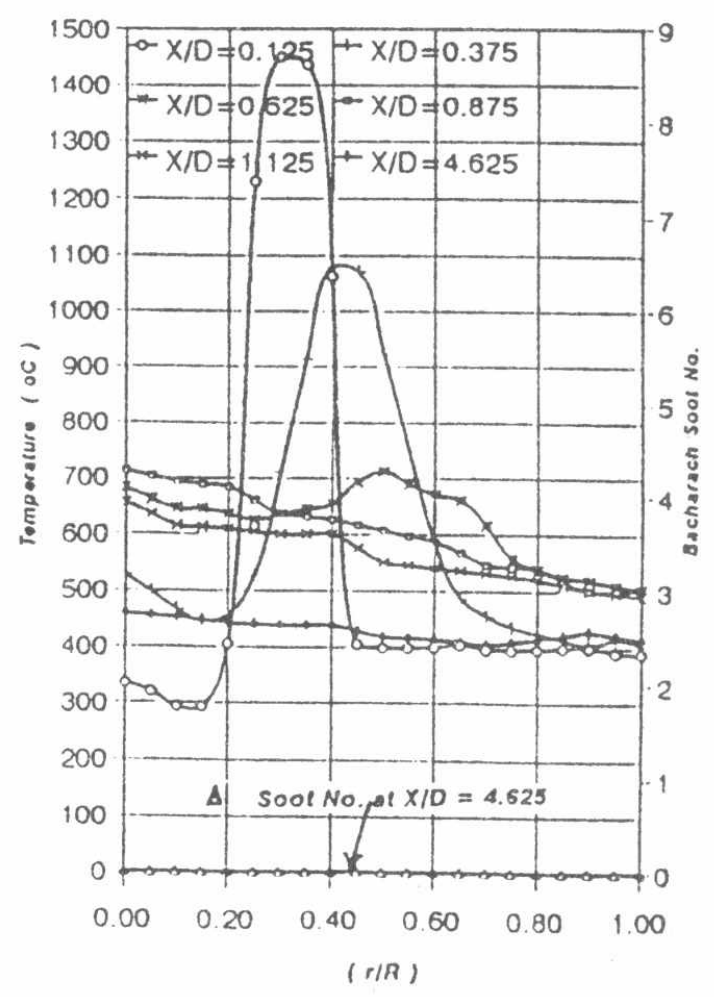

(c) - Run 6

Fig. 5 Radial Proflles of Temperature at Different Axlal Locatlons and Soot Concentration at Combustor Exit - Runs 4,5,6.

Fuel Typo: Gaseous Fuel (LPG) - Gaseous Fuel Ratlo $=100 \%$.

(a) Heat input $=29 \mathrm{~kW}$

(b) Heat Input $=38 \mathrm{~kW}$

(c) Heat input $=48 \mathrm{~kW}$ 


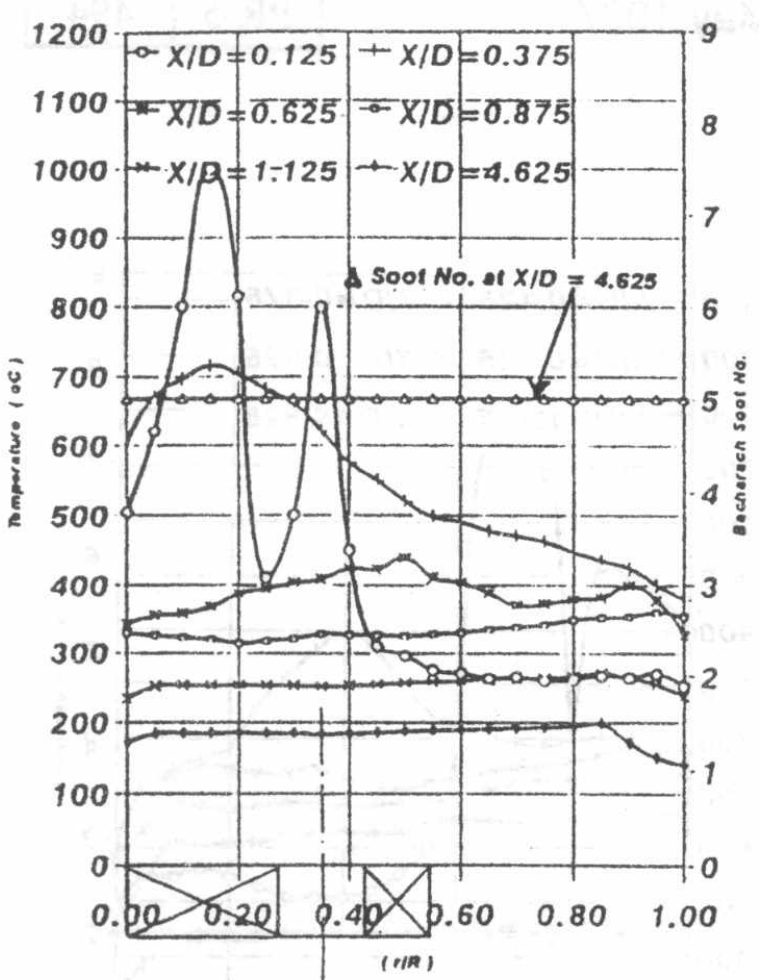

(a) - Run 7

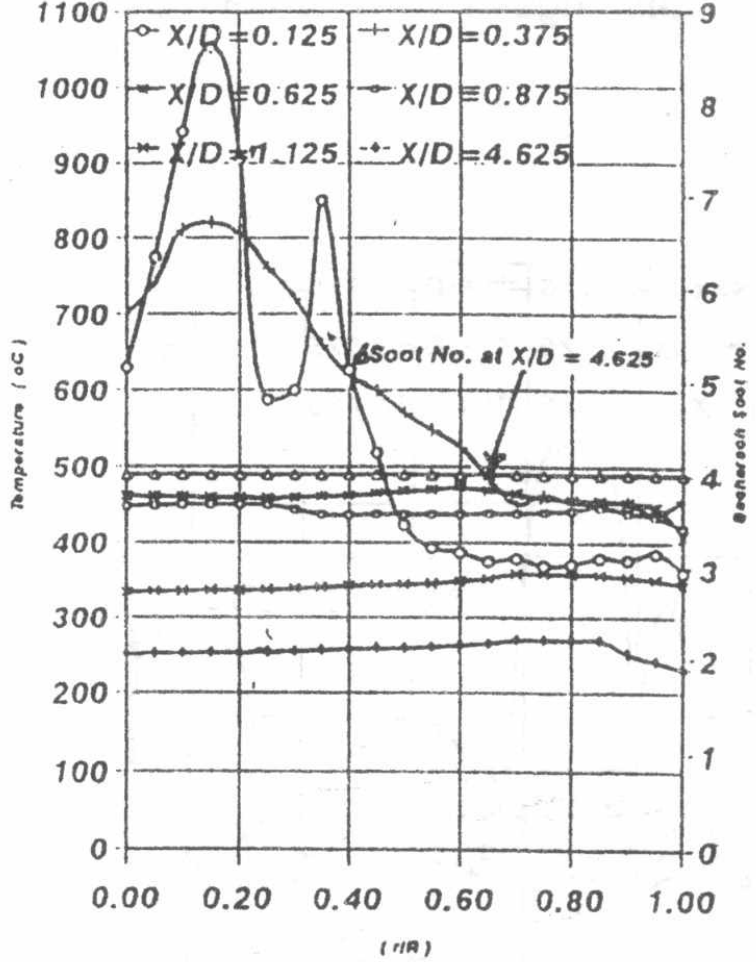

(b) - Run 8

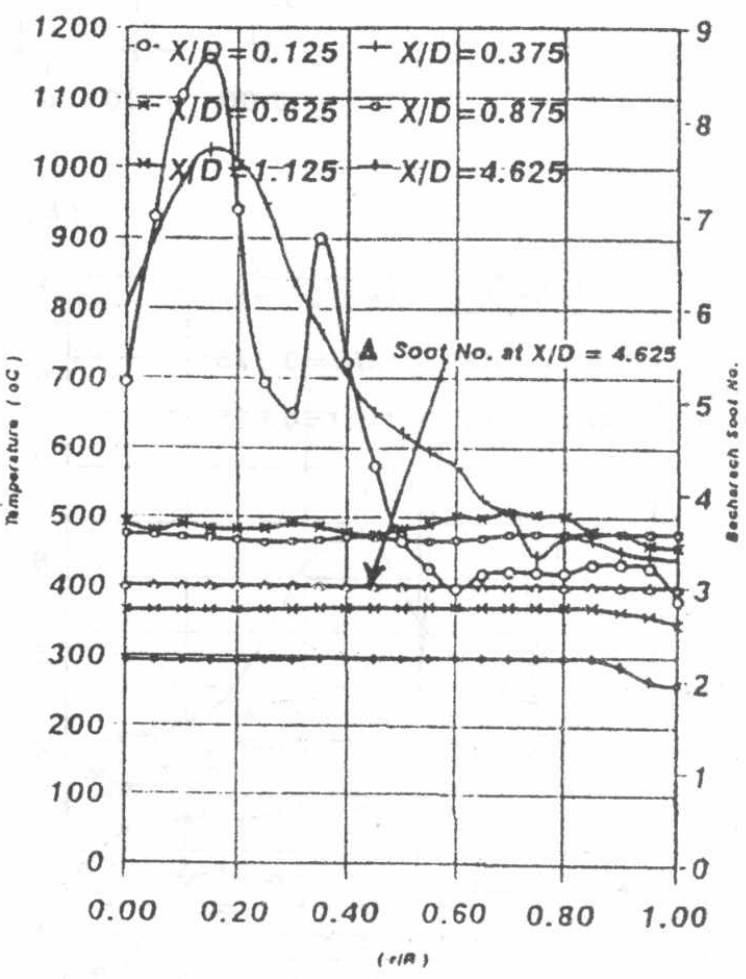

(c) - Run 9

Fig. 6 Radial Proflles of Temperature at Different Axial Locations and Soot Concentration at Combustor Exit - Runs 7,8,9.

Fuel Type : Dual Fuel - Gaseous Fuel Ratlo $=25 \%$ - Equlvalence Rat1o( $\phi)-0.833$
(a) Heat Input $=29 \mathrm{~kW}$
(b) Heat Input $=38 \mathrm{~kW}$
(c) Heat Input $=48 \mathrm{~kW}$ 


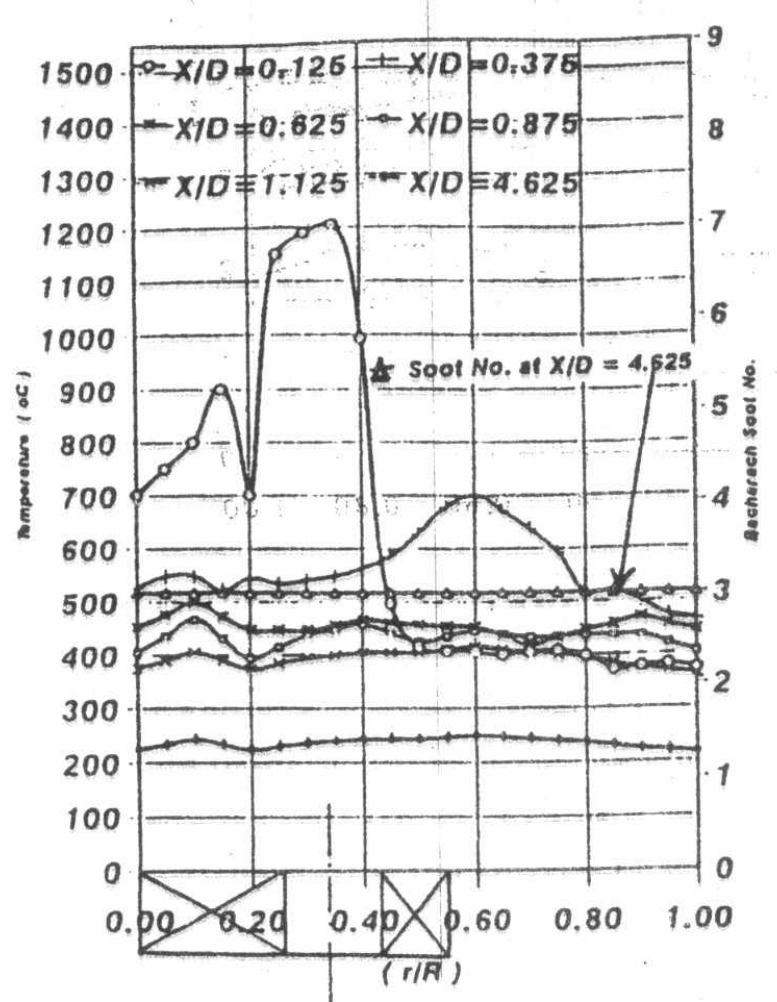

(a). Run 10

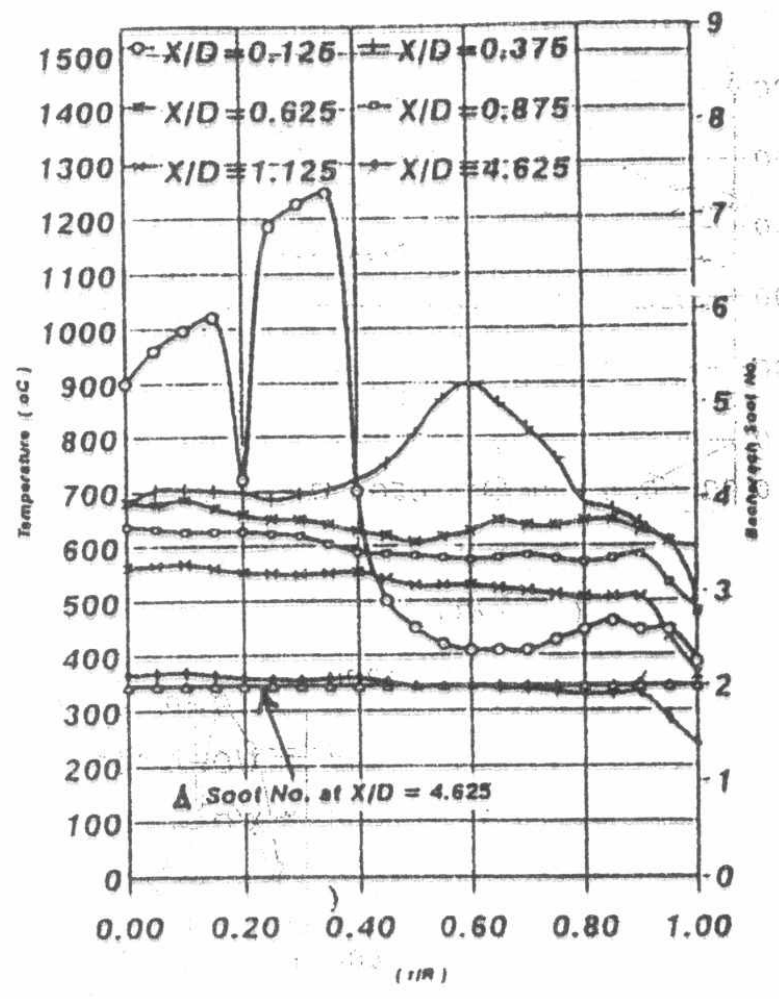

(b), Run 11

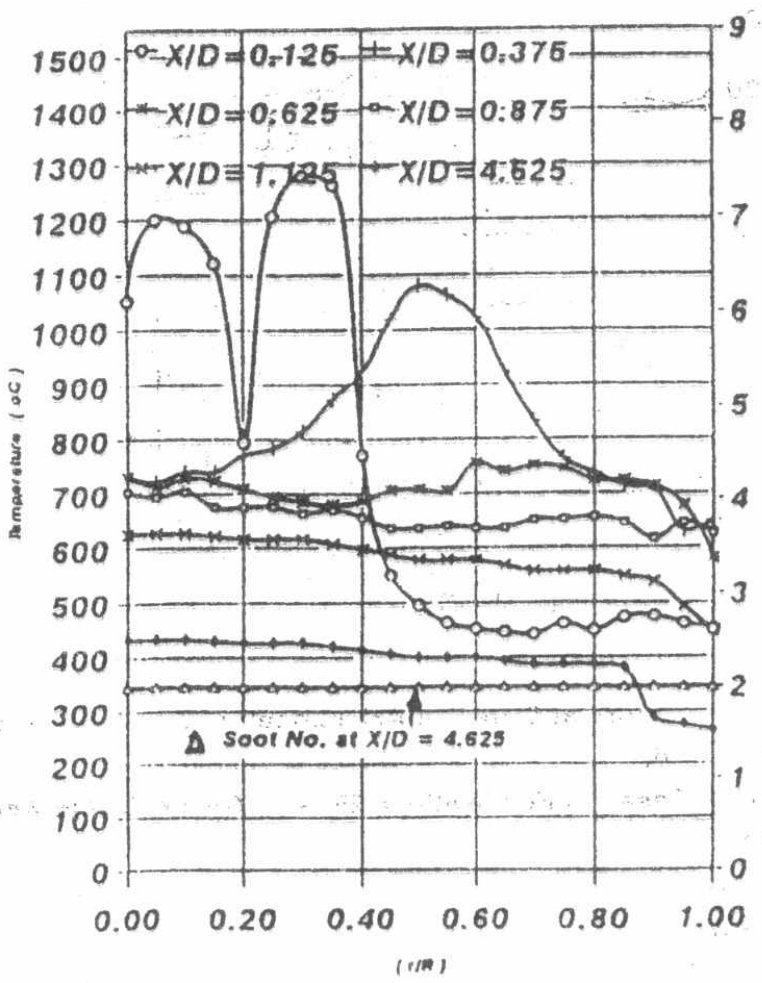

(c) - Run 12

Fig. 7 Radial Proflies of Temperature at Different Axlal Locatlons and Soot Concentration at Combustor Exlt - Runs 10,11,12.

Fuel Type: Dual Fuel - Gaseous Fuel Ratio $=50 \%$ - Equivalence Rat $10(\$)-0.833$

(a) Heat input $=29 \mathrm{~kW}$

(b) Heat input $=38 \mathrm{~kW}$ 


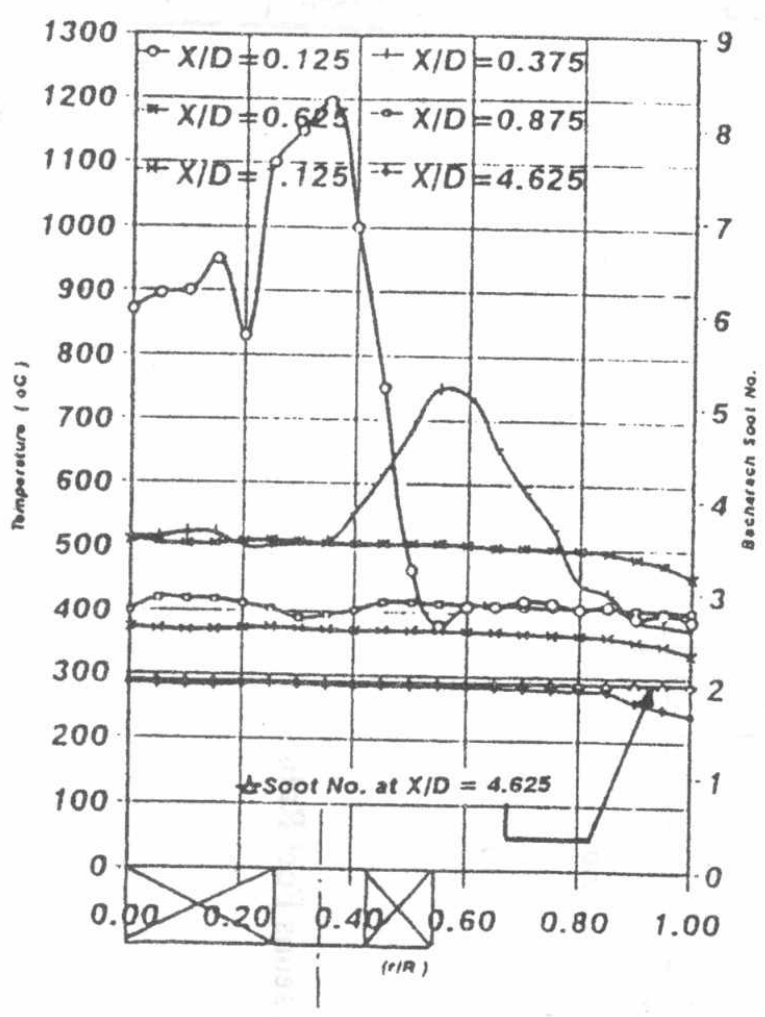

(a) - Run 13

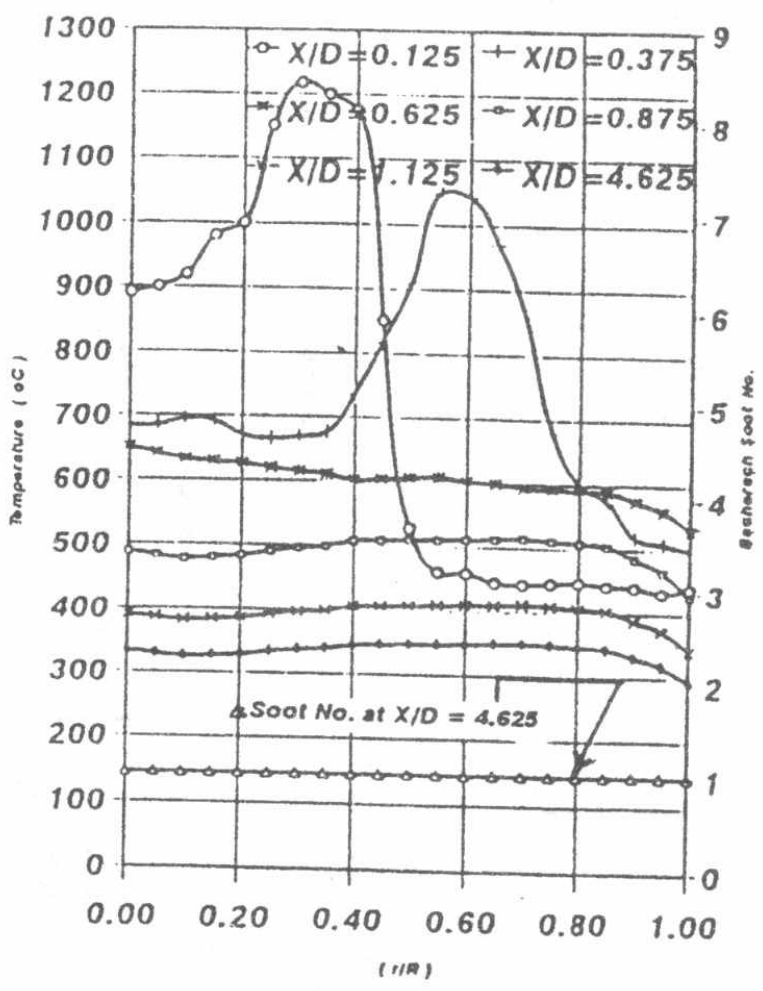

(b) - Run 14

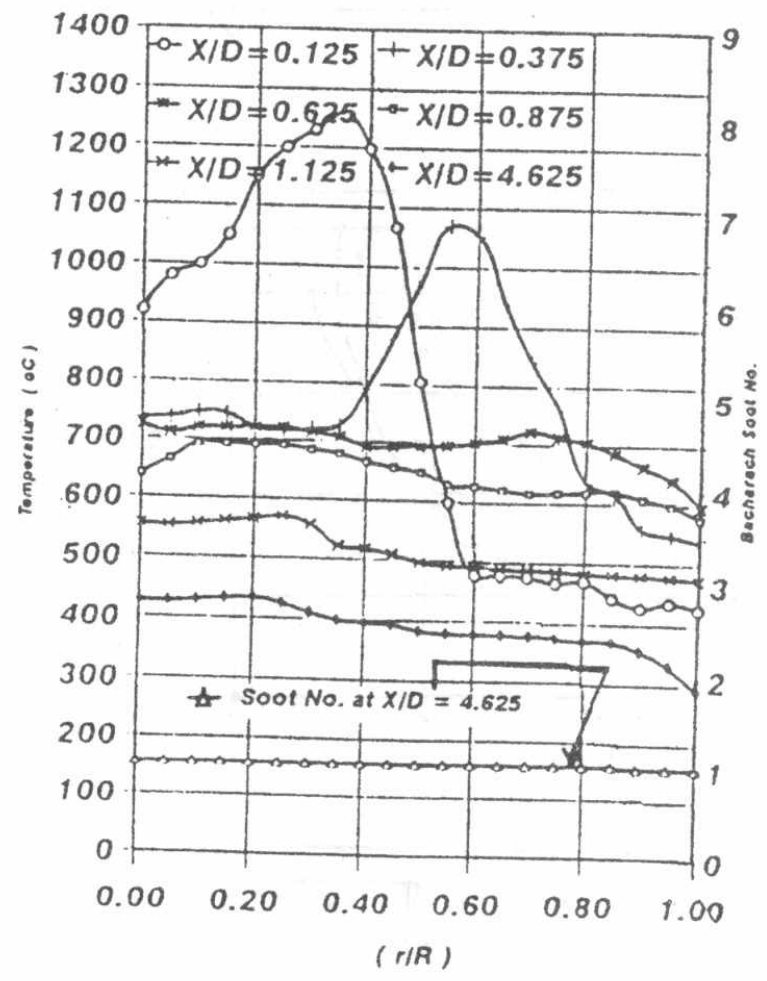

(c) - Run 15

Fig. 8 Radlal Proflles of Temperature at Different Axlal Locations and Soot Concentration at Combustor Exit - Runs 13,14,15.

Fuel Type : Dual Fuel - Gaseous Fuel Ratlo $=75 \%$. Equivalence Rat

(a) Heat input $=29 \mathrm{~kW}$

(b) Heat Input $=38 \mathrm{~kW}$

(c) Heat Input $=48 \mathrm{~kW}$ 
Proceedings of the $7^{\text {th }}$ ASAT Conf. 13-15 May 1997
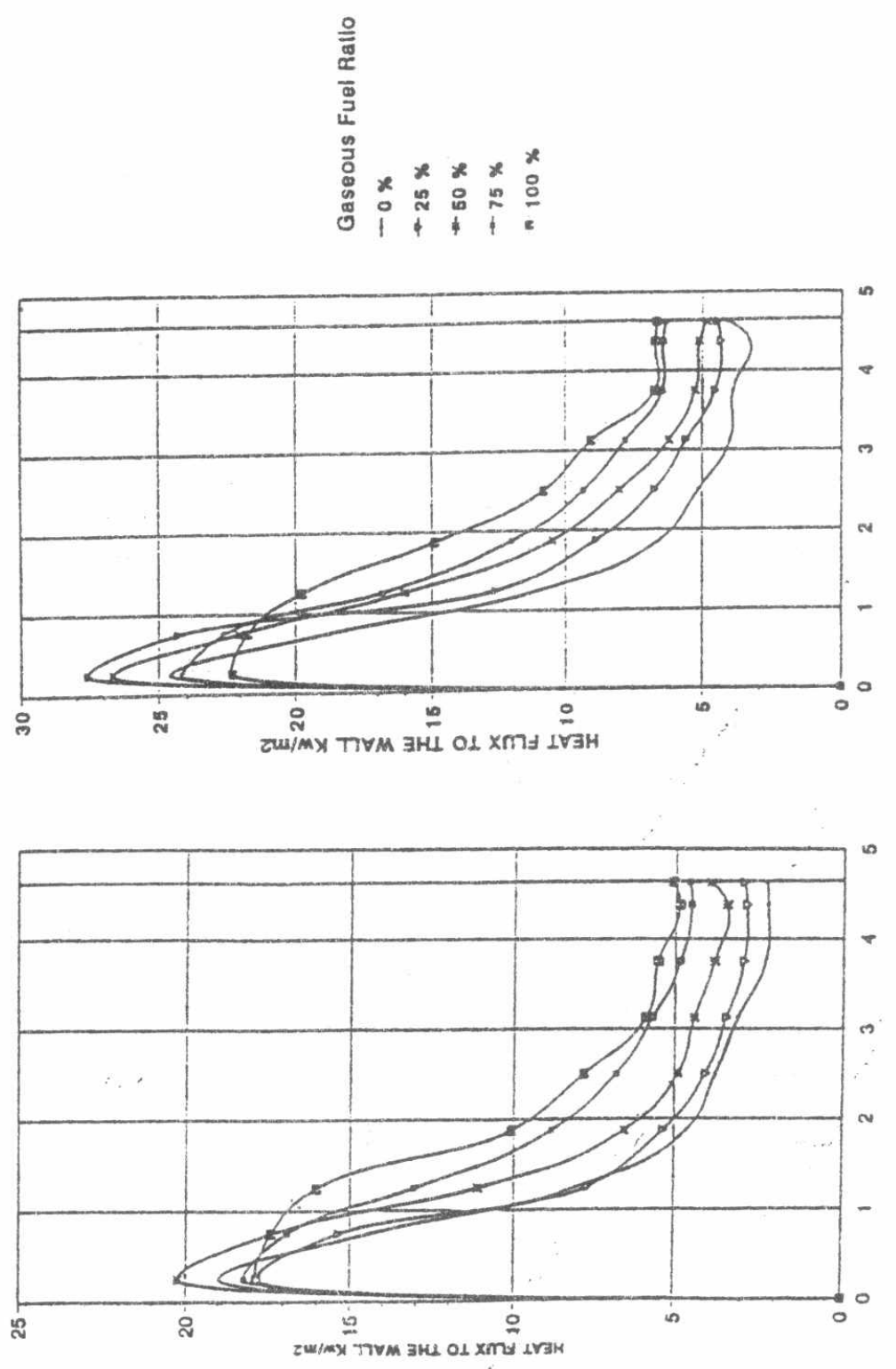

อ
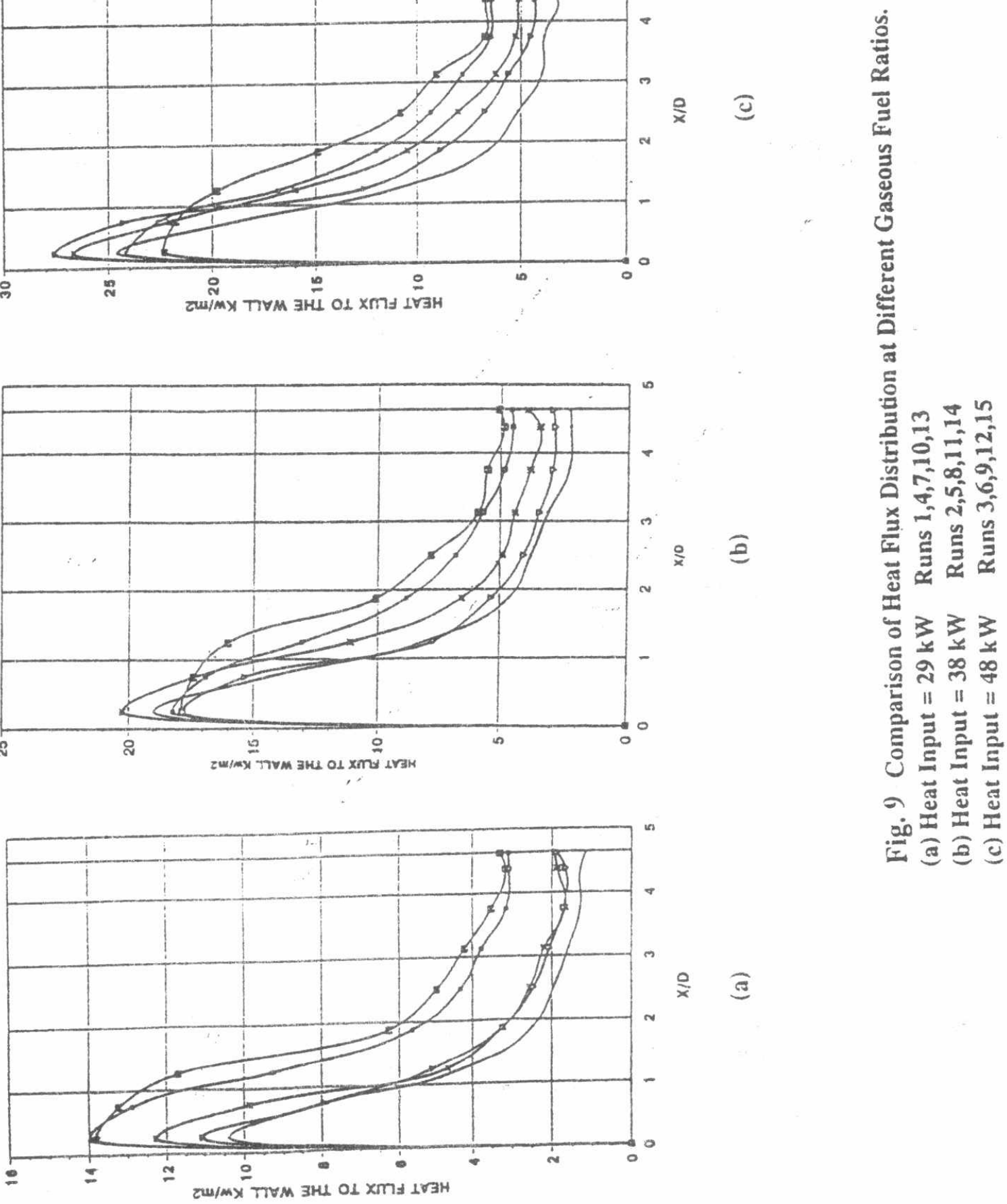

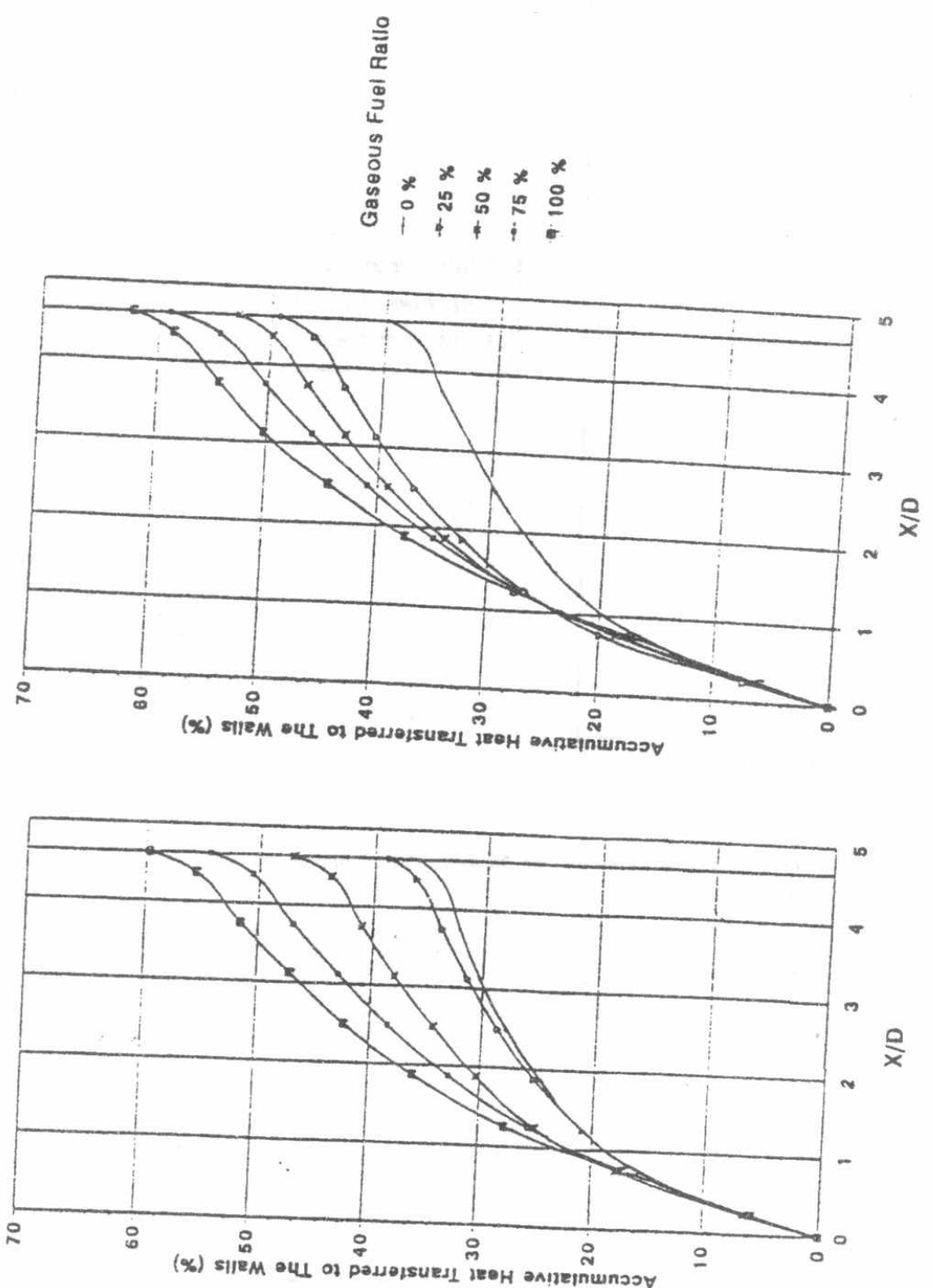

a

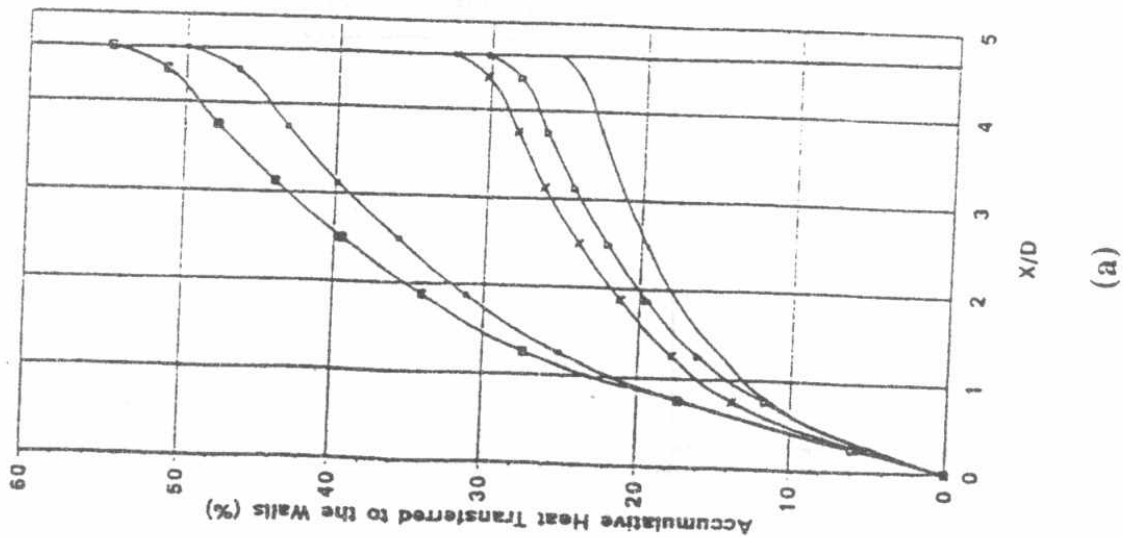

()

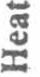

I $\approx n$

ต่

हैं

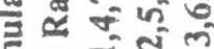

है

+ 。

I

○ी

站

ํํㄴ II II ||

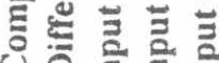

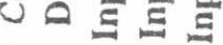

- $\vec{\exists} \tilde{\Xi}$

i I $\stackrel{ \pm}{2}$

$\therefore$ 을

\%) S|l 


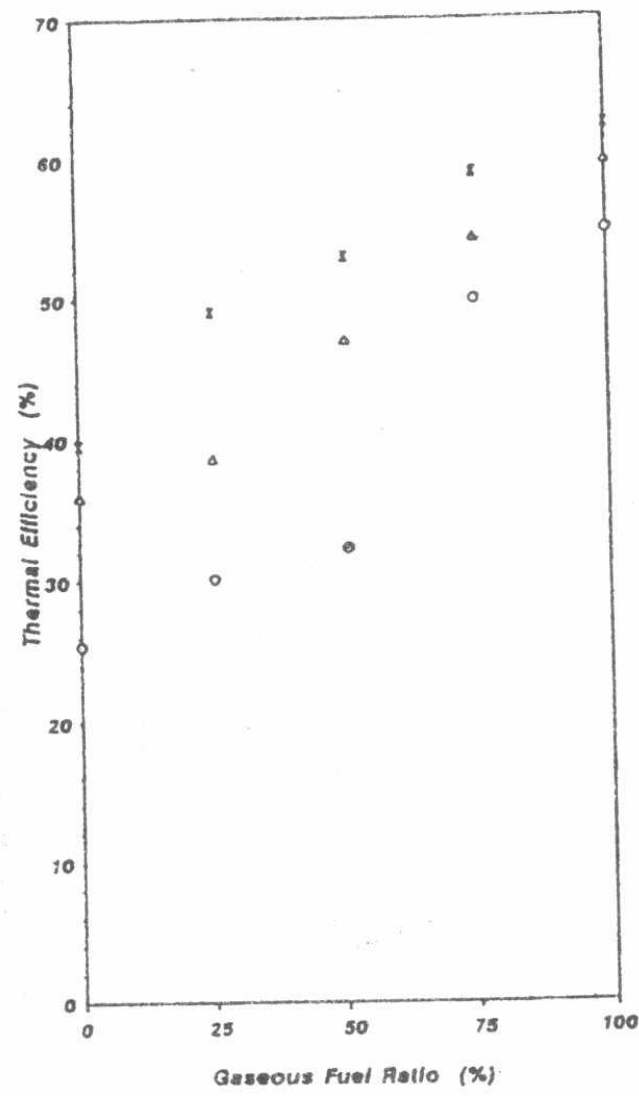

- heAT INPUT $=29 \mathrm{~kW}$

- heAT INPUT $=38 \mathrm{~kW}$

8 HEAT INPUT $=48 \mathrm{~kW}$

Fig. 11 Comperison Between Thermal Elliclencies st Dillerent D̈pes of Fuel and at Different Heat inputs.

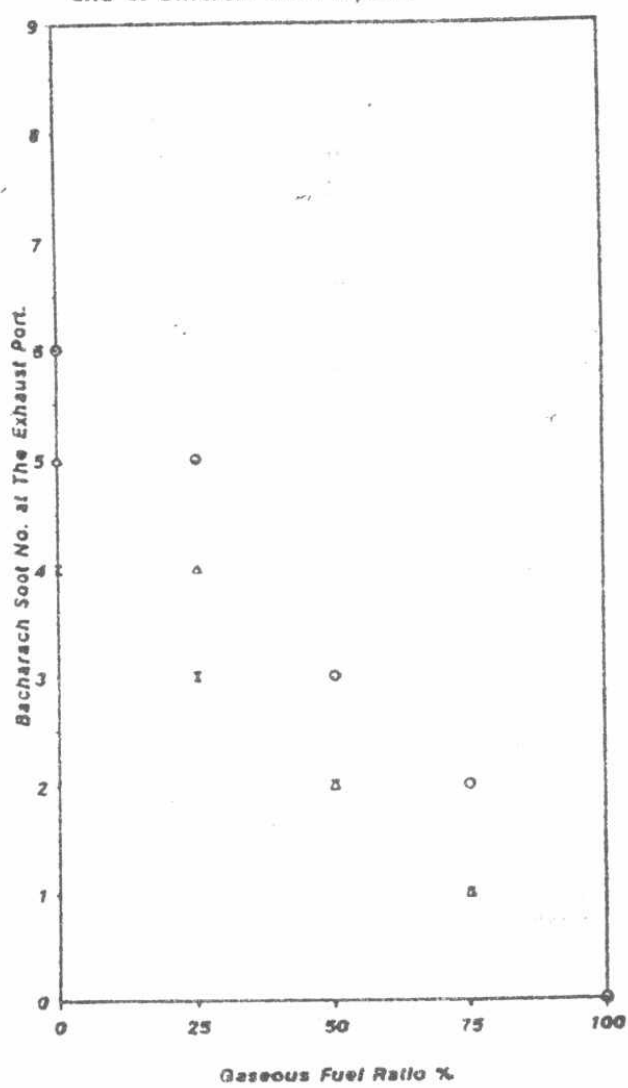

- HEAT INPUT $=29 \mathrm{~kW}$

$\triangle$ HEAT INPUT $=$ JA $k W$

1 HEAT INPUT = AE kW

Fig. 12' Comparison Between Soot Concentration of the Exhaust Port at Different Mypes of Fuel end at Different Heat inputs 